\title{
Lanthanopolyoxotungstates in silica nanoparticles: multi-wavelength photoluminescent core/shell materials $\dagger$
}

\author{
Carlos M. Granadeiro, ${ }^{a}$ Rute A. S. Ferreira, ${ }^{b}$ Paula C. R. Soares-Santos, ${ }^{a b}$ Luís D. Carlos, ${ }^{b}$ Tito Trindade \\ and Helena I. S. Nogueira $* a$
}

\author{
Received 21st September 2009, Accepted 4th February 2010 \\ First published as an Advance Article on the web 8th March 2010 \\ DOI: $10.1039 / b 919691 a$
}

\begin{abstract}
Photoluminescent lanthanopolyoxotungstate core/shell nanoparticles are prepared by the encapsulation of lanthanide-containing polyoxometalates (POMs) with amorphous silica shells. The preparation of morphological well-defined core/shell nanoparticles is achieved by the hydrolysis of tetraethoxysilane in the presence of POMs using a reverse microemulsion method. The POMs used are decatungstolanthanoates of $\left[\mathrm{Ln}\left(\mathrm{W}_{5} \mathrm{O}_{18}\right)_{2}\right]^{9-}$ type $(\mathrm{Ln}(\mathrm{III})=\mathrm{Eu}, \mathrm{Gd}$ and $\mathrm{Tb})$. Photoluminescence studies show that there is efficient emission from the POM located inside the $\mathrm{SiO}_{2}$ shells, through excitation paths that involve $\mathrm{O} \rightarrow \mathrm{Eu} / \mathrm{Tb}$ and $\mathrm{O} \rightarrow \mathrm{W}$ ligand-to-metal charge transfer. It is also shown that the excitation of the POM containing europium(III) may be tuned towards longer wavelengths via an antenna effect, by coordination of an organic ligand such as 3-hydroxypicolinate. The POM/SiO 2 nanoparticles form stable suspensions in aqueous solution having the advantage of POM stabilization inside the core and the possibility of further surface grafting of chemical moieties via well known derivatization procedures for silica surfaces. These features together with the possibility of tuning the excitation wavelength by modifying the coordination sphere in the lanthanopolyoxometalate, make this strategy promising to develop a new class of optical bio-tags composed of silica nanobeads with multi-wavelength photoluminescent lanthanopolyoxometalate cores.
\end{abstract}

\section{Introduction}

Core/shell systems have been widely used in recent years, considering a series of advantages for specific applications, ${ }^{\mathbf{1}, 2}$ which include new clinical diagnosis platforms. ${ }^{3-5}$ The encapsulation of several types of nanoparticles with amorphous $\mathrm{SiO}_{2}$ shells, using either the Stöber method $^{6}$ or the microemulsion synthesis, ${ }^{7}$ has become a widespread technique. ${ }^{8,9}$ The high surface area-to-volume ratio, along with the relatively ease of surface functionalization of core/shell $\mathrm{SiO}_{2}$ nanoparticles, allows their extensive use in the fabrication of biosensors, ${ }^{\mathbf{1 0}-\mathbf{1 2}}$ cell labelling ${ }^{13,14}$ and drug delivery systems. ${ }^{15,16}$ Lanthanopolyoxometalate-based materials have been investigated in particular due to their photoluminescent properties. Lanthanopolyoxometalates have been assembled in Langmuir-Blodgett films ${ }^{17,18}$ and in layer-by-layer deposition films, ${ }^{19,20}$ or incorporated in double layer hydroxides ${ }^{21}$ and in liquid crystals, ${ }^{22}$ envisaging new optically active materials. Polyoxometalates (POMs) have also been used in the fabrication of siliceous sol-gel hybrid materials. ${ }^{23}$ Green et al. ${ }^{24,25}$ reported the synthesis of Stöber type $\mathrm{SiO}_{2}$ nanospheres doped with $\mathrm{Na}_{13}\left[\mathrm{Eu}\left(\mathrm{SiMoW}_{10} \mathrm{O}_{39}\right)_{2}\right]$, using a POM/ poly-L-lysine conjugate. The POM/poly-L-lysine conjugate favoured the formation of hollow spherical nanocomposites, hence

\footnotetext{
a Department of Chemistry, CICECO, University of Aveiro, 3810-193 Aveiro, Portugal. E-mail: helenanogueira@ua.pt

${ }^{b}$ Department of Physics, CICECO, University of Aveiro, 3810-193 Aveiro, Portugal

$\dagger$ Electronic supplementary information (ESI) available: FT-IR and FT-Raman spectra, additional HRTEM images and complementary photoluminescence spectra details. See DOI: 10.1039/b919691a
}

leading to an appealing system for optical monitoring of drug carriers. The latter work also reported $\mathrm{SiO}_{2}$ nanospheres containing POMs evenly spread throughout the particle that were prepared by an alcosol route.

The preparation of POM-containing dense core/shell nanoparticles, not hollow and with a well-defined polyoxometalate core, is reported for the first time in the work presented here. Following our own studies of coupling lanthanide complexes, mainly of $\mathrm{Eu}(\mathrm{III})$ and $\mathrm{Tb}(\mathrm{III})$, to $\mathrm{SiO}_{2}$ nanoparticles, ${ }^{26}$ we report here the preparation of core/shell $\mathrm{POM} / \mathrm{SiO}_{2}$ nanocomposites. Comparing to previous work with $\mathrm{Ln}$ (III) 3-hydroxypicolinate complexes, ${ }^{26}$ here the use of microemulsions as nanoreactors and Ln(III) polyoxometalate compounds allowed a better control of the morphological properties of the composite nanoparticles.

The POMs used here as starting materials were decatungstolanthanoates of $\left[\mathrm{Ln}\left(\mathrm{W}_{5} \mathrm{O}_{18}\right)_{2}\right]^{9-}$ type $(\mathrm{Ln}(\mathrm{III})=\mathrm{Eu}, \mathrm{Gd}$ and $\mathrm{Tb})$. The $\left[\mathrm{Eu}\left(\mathrm{W}_{5} \mathrm{O}_{18}\right)_{2}\right]^{9-}$ anion exhibits peculiar photoluminescence features, in particular, an abnormally high intensity of the ${ }^{5} \mathrm{D}_{0} \rightarrow{ }^{7} \mathrm{~F}_{4}$ transition, which has been modelled by some of us in terms of the $\Omega_{\lambda}$ intensity parameters. ${ }^{27}$ An interesting and general feature of these $\mathrm{POM} / \mathrm{SiO}_{2}$ core/shell systems is the possibility to tune their optical properties by working on the coordination chemistry of the inner lanthanide complexes, varying the lanthanide centers or adding coordinated organic ligands. An organic-inorganic hybrid based on the europium(III) decatungstolanthanoate and 3-hydroxypicolinic acid ${ }^{28}$ was also encapsulated in nanosilica. The 3-hydroxypicolinate ligand (picOH) acts as an antenna collecting photons and transferring energy to the lanthanide center, which leads to excitation wavelength tunning for photoluminescent nanosilicas containing 
these compounds. Mixed lanthanide nanocomposites with a $1: 1$ stoichiometry of either $\mathrm{Eu}: \mathrm{Tb}$ or $\mathrm{Eu}: \mathrm{Gd}$ were also prepared. The POMs, along with the POMs encapsulated in the nanosilica, were studied by photoluminescence. The effect of the organic ligand on the luminescence of the lanthanopolyoxotungstate inside the $\mathrm{SiO}_{2}$ shell was also investigated.

\section{Experimental}

\section{Materials and chemicals}

All reagents were purchased from Aldrich and used without further purification. The POMs $\mathrm{Na}_{9}\left[\mathrm{Eu}\left(\mathrm{W}_{5} \mathrm{O}_{18}\right)_{2}\right] \cdot 14 \mathrm{H}_{2} \mathrm{O}$, $\mathrm{Na}_{9}\left[\mathrm{Gd}\left(\mathrm{W}_{5} \mathrm{O}_{18}\right)_{2}\right] \cdot 20 \mathrm{H}_{2} \mathrm{O}$ and $\mathrm{Na}_{9}\left[\mathrm{~Tb}\left(\mathrm{~W}_{5} \mathrm{O}_{18}\right)_{2}\right] \cdot 14 \mathrm{H}_{2} \mathrm{O}$ were prepared using the method described by Peacock and Weakley. ${ }^{29}$

\section{Instrumentation and characterization}

Infrared spectra were obtained on a Mattson 7000 spectrophotometer using $\mathrm{KBr}$ pellets. FT-Raman spectra were recorded using a Bruker RFS100/S FT-Raman spectrometer (Nd:YAG laser, $1064 \mathrm{~nm}$ excitation). TEM images were obtained using a Hitachi H-9000 transmission electron microscope operating at an acceleration voltage of $300 \mathrm{kV}$. High-resolution TEM (HRTEM) and elemental mapping by X-ray energy dispersive spectroscopy (EDX) analysis were carried out with a JEOL 2200FS transmission electron microscope operating at an acceleration voltage of $200 \mathrm{kV}$.

The photoluminescence spectra were recorded between $12 \mathrm{~K}$ and room temperature on a Fluorolog-3 Model FL3 - 2T with double excitation spectrometer and a single emission spectrometer (TRIAX 320) coupled to a R928 photomultiplier, using a front face acquisition mode. The excitation source was a $450 \mathrm{~W}$ Xenon lamp. Emission was corrected for the spectral response of the monochromators and the detector using typical correction spectrum provided by the manufacturer and the excitation spectra were corrected for the spectral distribution of the lamp intensity using a photodiode reference detector. The lifetime measurements were acquired at room temperature with the setup described for the luminescence spectra using a pulsed $\mathrm{Xe}-\mathrm{Hg}$ lamp ( $6 \mu$ s pulse at half width and 20-30 $\mu$ s tail). The absolute emission quantum yields were measured at room temperature using a quantum yield measurement system C9920-02 from Hamamatsu with a $150 \mathrm{~W}$ Xenon lamp coupled to a monochromator for wavelength discrimination, an integrating sphere as sample chamber and a multi channel analyzer for signal detection. Three measurements were made for each sample so that the average value is reported. The method is accurate to within $10 \%$.

\section{Preparation of $\mathrm{POM} / \mathrm{SiO}_{2}$ nanocomposites}

The nanocomposites were prepared by a reverse microemulsion method (W/O, water in oil microemulsions) for the hydrolysis of tetraethoxysilane (TEOS). ${ }^{7} \mathrm{~A}$ W/O microemulsion containing Triton X-100 (3.68 mmol), 1-octanol (14.4 mmol), cyclohexane $(86.1 \mathrm{mmol})$, TEOS $(200 \mu \mathrm{L})$ and a POM $(0.016 \mathrm{mmol})$ aqueous solution $\left(1 \mathrm{~mL} \mathrm{H}_{2} \mathrm{O}\right)$ was mixed with a W/O microemulsion containing Triton X-100 (3.68 mmol), 1-octanol (14.4 mmol), cyclohexane $(86.1 \mathrm{mmol})$ and ammonia $(200 \mu \mathrm{L})$. The mixture was stirred for $24 \mathrm{~h}$ at room temperature, after which acetone was added in order to precipitate the nanoparticles. The white solid obtained was centrifuged, washed with ethanol and water, and dried in a desiccator under vacuum. The POMs used in the preparation of the nanocomposites (see Table 1 for numbering) were respectively: $\mathrm{Na}_{9}\left[\mathrm{Eu}\left(\mathrm{W}_{5} \mathrm{O}_{18}\right)_{2}\right] \cdot 14 \mathrm{H}_{2} \mathrm{O}$ for 1, $\mathrm{Na}_{9}[\mathrm{~Tb}-$ $\left.\left(\mathrm{W}_{5} \mathrm{O}_{18}\right)_{2}\right] \cdot 14 \mathrm{H}_{2} \mathrm{O}$ for $2, \mathrm{Na}_{9}\left[\mathrm{Gd}\left(\mathrm{W}_{5} \mathrm{O}_{18}\right)_{2}\right] \cdot 20 \mathrm{H}_{2} \mathrm{O}$ for 3 , a $1: 1$ mixture of the latter $\mathrm{Eu}$ and $\mathrm{Tb}$ POMs in aqueous solution for $\mathbf{4}$, a $1: 1$ mixture of the latter Eu and Gd POMs in aqueous solution for 5 , the hybrid organic-inorganic compound $\mathrm{Na}_{13}[\mathrm{Eu}-$ $\left.\left(\mathrm{W}_{5} \mathrm{O}_{18}\right)_{2}(\mathrm{picOH})_{4}\right] \cdot 15 \mathrm{H}_{2} \mathrm{O}$ for 6 .

\section{Preparation of $\mathrm{Na}_{13}\left[\mathrm{Eu}\left(\mathrm{W}_{5} \mathrm{O}_{18}\right)_{2}(\mathrm{picOH})_{4}\right] \cdot 15 \mathrm{H}_{2} \mathrm{O}$}

The compound was prepared following our previous method. ${ }^{28}$ An aqueous solution of 3-hydroxypicolinic acid (3.04 mmol, in $30 \mathrm{~mL}$ of water) was added to an aqueous solution of sodium tungstate dihydrate $(15.2 \mathrm{mmol}$, in $7 \mathrm{~mL}$ of water). The mixture was heated to $90{ }^{\circ} \mathrm{C}$ with stirring and a hot aqueous solution of europium(III) nitrate (1.52 mmol, in $2 \mathrm{~mL}$ of water) was slowly added. The resulting mixture was stirred and kept at $90{ }^{\circ} \mathrm{C}$ for $30 \mathrm{~min}$. The mixture was allowed to cool at room temperature and the solid obtained was filtered, washed with ethanol and dried in a desiccator over silica gel.

\section{Results and discussion}

Core/shell $\mathrm{POM} / \mathrm{SiO}_{2}$ nanoparticles were obtained by the hydrolysis of tetraethoxysilane (TEOS) in the presence of POMs through a reverse microemulsion method. ${ }^{7}$ The POMs used as starting materials were the sodium salts of lanthanopolyoxotungstates $\left[\mathrm{Ln}\left(\mathrm{W}_{5} \mathrm{O}_{18}\right)_{2}\right]^{9-}$ with $\mathrm{Ln}(\mathrm{III})=\mathrm{Eu}, \mathrm{Gd}$ and $\mathrm{Tb}$. A POM derived from $\left[\mathrm{Eu}\left(\mathrm{W}_{5} \mathrm{O}_{18}\right)_{2}\right]^{9-}$ and 3-hydroxypicolinic acid was also synthesized $\left(\mathrm{Na}_{13}\left[\mathrm{Eu}\left(\mathrm{W}_{5} \mathrm{O}_{18}\right)_{2}(\mathrm{picOH})_{4}\right] \cdot 15 \mathrm{H}_{2} \mathrm{O}\right)$ and

Table 1 Spectroscopic data (FT-IR and FT-Raman) for the POMs used as starting materials and the corresponding silica nanocomposites

\begin{tabular}{|c|c|c|}
\hline \multirow[b]{2}{*}{ Compound } & \multicolumn{2}{|c|}{ Vibrational spectra/ $\mathrm{cm}^{-1 a}$} \\
\hline & $\nu(\mathrm{W}=\mathrm{O})$ & $\nu(\mathrm{W}-\mathrm{O}-\mathrm{W})$ \\
\hline $\mathrm{Na}_{9}\left[\mathrm{Eu}\left(\mathrm{W}_{5} \mathrm{O}_{18}\right)_{2}\right] \cdot 14 \mathrm{H}_{2} \mathrm{O}$ & $\begin{array}{l}937 \mathrm{vs} \\
945 \mathrm{vs}\end{array}$ & $\begin{array}{l}846 \text { vs, } 788 \text { vs, } 705 \text { vs } \\
892 s\end{array}$ \\
\hline $\mathrm{Na}_{9}\left[\mathrm{~Tb}\left(\mathrm{~W}_{5} \mathrm{O}_{18}\right)_{2}\right] \cdot 14 \mathrm{H}_{2} \mathrm{O}$ & $\begin{array}{l}938 \mathrm{~s} \\
946 v s\end{array}$ & $\begin{array}{l}844 \mathrm{vs}, 786 \mathrm{~s}, 706 \mathrm{~s} \\
894 \mathrm{~s}\end{array}$ \\
\hline $\mathrm{Na}_{9}\left[\mathrm{Gd}\left(\mathrm{W}_{5} \mathrm{O}_{18}\right)_{2}\right] \cdot 20 \mathrm{H}_{2} \mathrm{O}$ & $\begin{array}{l}935 \mathrm{vs} \\
956 \mathrm{vs}\end{array}$ & $\begin{array}{l}844 \mathrm{vs}, 792 \mathrm{~s}, 706 \mathrm{vs} \\
893 \mathrm{~s}\end{array}$ \\
\hline$\left[\mathrm{Eu}\left(\mathrm{W}_{5} \mathrm{O}_{18}\right)_{2}\right] / \mathrm{SiO}_{2}(\mathbf{1})$ & $\begin{array}{l}943 \mathrm{~m} \\
954 \mathrm{vs}\end{array}$ & $\begin{array}{l}883 \mathrm{~m} \\
888 \mathrm{~m}\end{array}$ \\
\hline$\left[\mathrm{Tb}\left(\mathrm{W}_{5} \mathrm{O}_{18}\right)_{2}\right] / \mathrm{SiO}_{2}(\mathbf{2})$ & $\begin{array}{l}947 \mathrm{~m} \\
961 \mathrm{~s}\end{array}$ & $\begin{array}{l}800 \mathrm{~m} \\
891 \mathrm{~m}\end{array}$ \\
\hline$\left[\mathrm{Gd}\left(\mathrm{W}_{5} \mathrm{O}_{18}\right)_{2}\right] / \mathrm{SiO}_{2}(3)$ & $\begin{array}{l}943 \mathrm{~m} \\
962 \mathrm{vs}\end{array}$ & $\begin{array}{l}825 \mathrm{sh} \\
880 \mathrm{w}\end{array}$ \\
\hline$\left[\mathrm{Eu}\left(\mathrm{W}_{5} \mathrm{O}_{18}\right)_{2} \mathrm{~Tb}\left(\mathrm{~W}_{5} \mathrm{O}_{18}\right)_{2}\right] / \mathrm{SiO}_{2}(\mathbf{4})$ & $\begin{array}{l}948 \mathrm{~m} \\
967 \mathrm{vs}\end{array}$ & $\begin{array}{l}869 \mathrm{~m} \\
882 \mathrm{~m}\end{array}$ \\
\hline$\left[\mathrm{Eu}\left(\mathrm{W}_{5} \mathrm{O}_{18}\right)_{2} \mathrm{Gd}\left(\mathrm{W}_{5} \mathrm{O}_{18}\right)_{2}\right] / \mathrm{SiO}_{2}(\mathbf{5})$ & $\begin{array}{l}944 \mathrm{~m} \\
969 \mathrm{vs}\end{array}$ & $\begin{array}{l}\text { hidden } \\
873 m\end{array}$ \\
\hline $\begin{array}{l}\mathrm{Na}_{13}\left[\mathrm{Eu}\left(\mathrm{W}_{5} \mathrm{O}_{18}\right)_{2}(\mathrm{picOH})_{4}\right] \cdot 15 \mathrm{H}_{2} \mathrm{O} \\
{\left[\mathrm{Eu}\left(\mathrm{W}_{5} \mathrm{O}_{18}\right)_{2}(\mathrm{picOH})_{4}\right] / \mathrm{SiO}_{2}(\mathbf{6})}\end{array}$ & $\begin{array}{l}933 \mathrm{~s} \\
946 \mathrm{vs} \\
\text { hidden } \\
949 \mathrm{~m}\end{array}$ & $\begin{array}{l}842 \mathrm{vs}, 800 \mathrm{~s}, 701 \mathrm{vs} \\
892 \mathrm{~s} \\
\text { hidden } \\
858 w\end{array}$ \\
\hline $\begin{array}{l}{ }^{a} \text { Raman data in italic; v: very, } \\
\text { shoulder. }\end{array}$ & ong, 1 & dium, w: weak, sh: \\
\hline
\end{tabular}


encapsulated within $\mathrm{SiO}_{2}$ shells. Table 1 lists the nanocomposites obtained in this work that are designated by $\mathrm{POM} / \mathrm{SiO}_{2}$ (the POM refers to the starting polyoxometalate anion). Also shown are the FT-IR and FT-Raman diagnostic bands for the POMs, as pure powders and in the respective $\mathrm{SiO}_{2}$ nanocomposites.

The presence of polyoxotungstates in the $\mathrm{POM} / \mathrm{SiO}_{2}$ nanocomposites is clearly shown by several bands in the 700$1000 \mathrm{~cm}^{-1}$ range in the infrared and Raman spectra (Table 1, and Fig. $\mathrm{S} 1$ and $\mathrm{S} 2$ in the ESI $\dagger$ ), on top of $\mathrm{SiO}_{2}$ vibrations. These bands are assigned to the POM terminal $\mathrm{W}=\mathrm{O}$ stretches $(933-$ $948 \mathrm{~cm}^{-1}$ ) and $\mathrm{W}-\mathrm{O}-\mathrm{W}$ stretching modes in edge-shared $\mathrm{WO}_{6}$ octahedra (701-894 $\left.\mathrm{cm}^{-1}\right){ }^{30,31}$ Raman spectra allow a better observation of the POM vibrational modes that are strongly hidden in the infrared spectra by the very intense bands due to amorphous silica. As will be discussed later, for each POM and derived nanocomposite, the lanthanide ion was also identified by photoluminescence.

The TEM images of the $\mathrm{POM} / \mathrm{SiO}_{2}$ composites show morphological uniform nanosized spheres, composed of a core of POM which is coated with amorphous $\mathrm{SiO}_{2}$ (Fig. 1, 2a and 3). In $\left[\mathrm{Eu}\left(\mathrm{W}_{5} \mathrm{O}_{18}\right)_{2}\right] / \mathrm{SiO}_{2}$ (1) (Fig. 1a and $1 \mathrm{~b}$ ) the nanospheres are typically $35 \mathrm{~nm}$ in diameter containing a POM core that is $18 \mathrm{~nm}$ wide. In nanocomposites $\left[\mathrm{Eu}\left(\mathrm{W}_{5} \mathrm{O}_{18}\right)_{2}(\mathrm{picOH})_{4}\right] / \mathrm{SiO}_{2} \quad$ (6) (Fig. 1c) the POM core is smaller, that is certainly due ${ }^{32}$ to a smaller ratio of POM:TEOS used in the synthesis of $\mathbf{6}$ due to the lower solubility of the starting POM-picOH hybrid. All the TEM images showed clear predominance of core/shell type particles with the POM assigned to the inner dark spots observed in the TEM images. EDX mapping confirmed the presence of tungsten from POMs mostly in the core and the presence of silica in all particle area (Fig. 2). The lanthanide ions were also detected by EDX and the corresponding peaks were located mainly in the particles cores (Fig. S3 and S4 in the ESI $\dagger$ ).

As compared to our previous systems, ${ }^{26}$ the rather uniform morphological characteristics of the nanocomposites reported here can be related to the type of surfactant used and the ionic nature of the lanthanide-containing species. We suggest that the
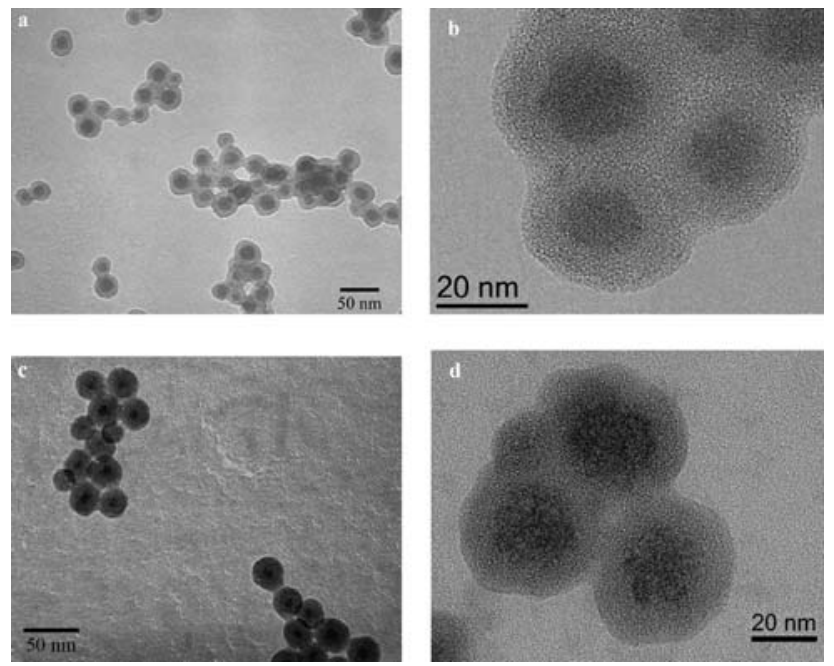

Fig. 1 TEM (a,c) and HRTEM (b,d) images of $(a, b)\left[\mathrm{Eu}\left(\mathrm{W}_{5} \mathrm{O}_{18}\right)_{2}\right] / \mathrm{SiO}_{2}$ (1), (c) $\left[\mathrm{Eu}\left(\mathrm{W}_{5} \mathrm{O}_{18}\right)_{2}(\mathrm{picOH})_{4}\right] / \mathrm{SiO}_{2}$ (6) and (d) $\left[\mathrm{Tb}\left(\mathrm{W}_{5} \mathrm{O}_{18}\right)_{2}\right] / \mathrm{SiO}_{2}$ (2) nanocomposites showing the core/shell structure of the particles.
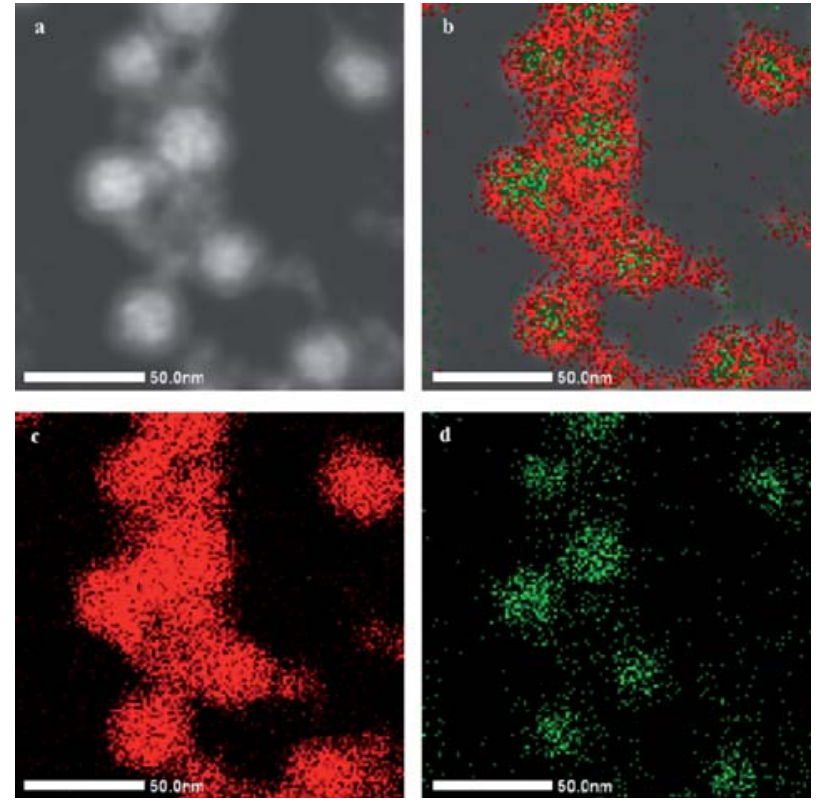

Fig. 2 HRTEM image of $\left[\mathrm{Tb}\left(\mathrm{W}_{5} \mathrm{O}_{18}\right)_{2}\right] / \mathrm{SiO}_{2}$ (2) nanocomposite in dark field mode (a) and with overlapping of EDX mapping for $\mathrm{Si}$ (red) and $\mathrm{W}$ (green) (b); separated EDX mapping for Si (c) and W (d).
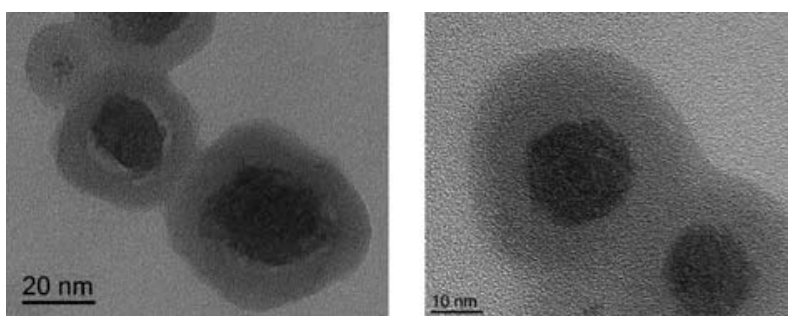

Fig. 3 HRTEM images of $\left[\mathrm{Gd}\left(\mathrm{W}_{5} \mathrm{O}_{18}\right)_{2}\right] / \mathrm{SiO}_{2}$ (3) nanocomposite.

non-ionic surfactant (Triton X-100) molecules favour the formation of $\mathrm{SiO}_{2}$ domains at the hydrophilic polyethylene oxide groups. As a consequence of condensation of the silica oligomers, resulting from TEOS hydrolysis at the W/O interface, the $\mathrm{SiO}_{2}$ domains grow from the inner surfaces of the nanoreactors towards the centre thus encapsulating the POM species that remained in the water pools and became trapped in their interior (Scheme 1). The POM species remain predominantly in the

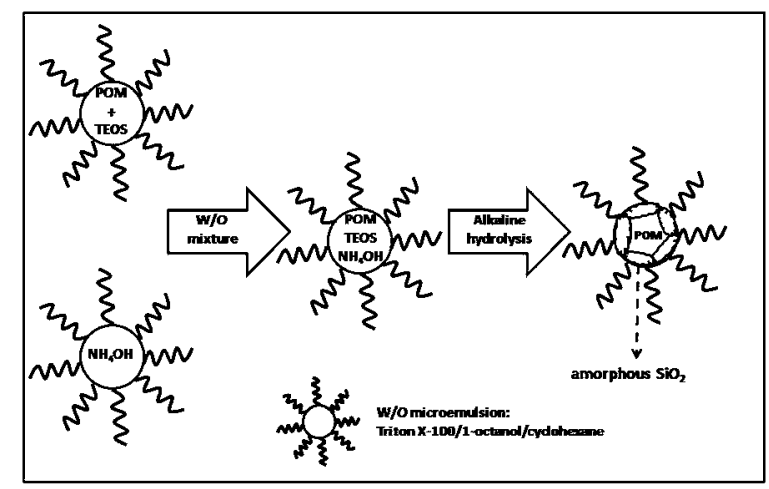

Scheme 1 Polyoxometalate (POM) encapsulation mechanism. 


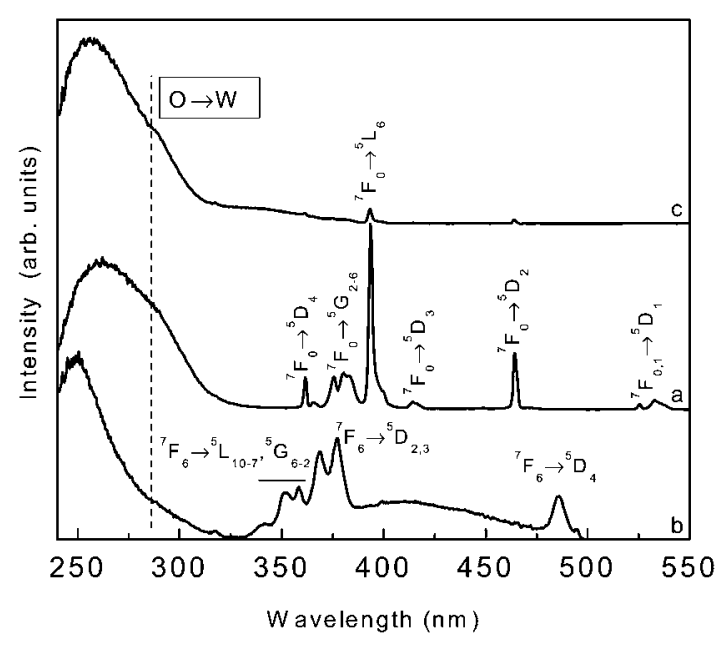

Fig. 4 Room temperature excitation spectra of the (a) $\left[\mathrm{Eu}\left(\mathrm{W}_{5} \mathrm{O}_{18}\right)_{2}\right] /$ $\mathrm{SiO}_{2}(\mathbf{1})$, (b) $\left[\mathrm{Tb}\left(\mathrm{W}_{5} \mathrm{O}_{18}\right)_{2}\right] / \mathrm{SiO}_{2}(2)$ and (c) $\left[\mathrm{Eu}\left(\mathrm{W}_{5} \mathrm{O}_{18}\right)_{2}(\mathrm{picOH})_{4}\right] / \mathrm{SiO}_{2}$ (6). The monitoring wavelengths were $544 \mathrm{~nm}$ and $611 \mathrm{~nm}$ for the $\mathrm{Tb}^{3+}$ and $\mathrm{Eu}^{3+}$-containing materials, respectively.

particles' core, thus suggesting that during the formation of the silica matrix the dispersion of the POM in the silica network occurs to a lesser extent. The latter case would lead presumably to particles with a uniform contrast in the TEM images or with the material spread evenly throughout the particle. ${ }^{24}$ Furthermore there was no evidence for the presence of more than one type of inorganic nanoparticles, for example composed of only $\mathrm{SiO}_{2}$ or chemically analogous composites, but with a distinct particle shape. Thus mixing the starting chemicals in two types of micelles, results in just one population of nanoreactors, in which the alkaline hydrolysis and condensation of TEOS is then kinetically controlled as in the conventional Stöber process. A proof consistent with this encapsulation mechanism was observed in the TEM images of a few particles in a $\left[\mathrm{Gd}\left(\mathrm{W}_{5} \mathrm{O}_{18}\right)_{2}\right] /$ $\mathrm{SiO}_{2}$ (3) nanocomposite sample (Fig. 3), where segregation of the POM core from the silica cover is observed. Still, the majority of
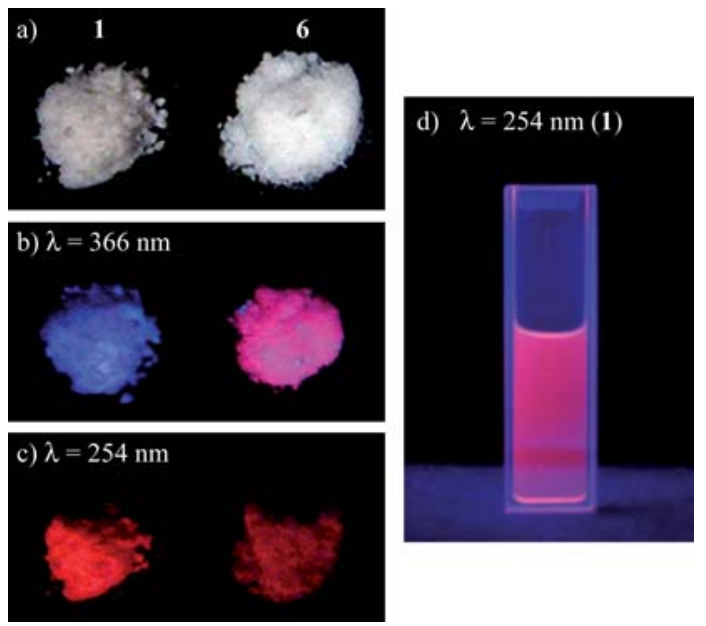

Fig. 5 Digital photographs of solid nanocomposites $\left[\mathrm{Eu}\left(\mathrm{W}_{5} \mathrm{O}_{18}\right)_{2}\right] / \mathrm{SiO}_{2}$ (1) (left) and $\left[\mathrm{Eu}\left(\mathrm{W}_{5} \mathrm{O}_{18}\right)_{2}(\mathrm{picOH})_{4}\right] / \mathrm{SiO}_{2}$ (6) (right) under (a) white light, (b) $366 \mathrm{~nm}$ and (c) $254 \mathrm{~nm}$ radiation; and (d) a suspension of $\mathbf{1}$ in ethanol under $254 \mathrm{~nm}$ radiation. The blue shadow is due to reflection of the UV light. the particles in the latter sample presented the same morphology as the other nanocomposites prepared, showing a full core of POM coated with amorphous $\mathrm{SiO}_{2}$.

The excitation spectra (Fig. 4) of the $\left[\mathrm{Eu}\left(\mathrm{W}_{5} \mathrm{O}_{18}\right)_{2}\right] / \mathrm{SiO}_{2}(\mathbf{1})$ and $\left[\mathrm{Tb}\left(\mathrm{W}_{5} \mathrm{O}_{18}\right)_{2}\right] / \mathrm{SiO}_{2}$ (2) compounds were monitored within the ${ }^{5} \mathrm{D}_{0} \rightarrow{ }^{7} \mathrm{~F}_{2}$ and ${ }^{5} \mathrm{D}_{4} \rightarrow{ }^{7} \mathrm{~F}_{5}$ transitions, respectively. The spectra display a broad band and a series of intra-4f lines ascribed to the ${ }^{7} \mathrm{~F}_{0,1} \rightarrow{ }^{5} \mathrm{D}_{1-4},{ }^{5} \mathrm{G}_{2-6},{ }^{5} \mathrm{~L}_{6}\left(\mathrm{Eu}^{3+}\right)$ and ${ }^{7} \mathrm{~F}_{6} \rightarrow{ }^{5} \mathrm{~L}_{10-7}$, ${ }^{5} \mathrm{G}_{6-2},{ }^{5} \mathrm{D}_{2-4}\left(\mathrm{~Tb}^{3+}\right)$ transitions. The broad band has a main component at 262 and $250 \mathrm{~nm}$ for the $\left[\mathrm{Eu}\left(\mathrm{W}_{5} \mathrm{O}_{18}\right)_{2}\right] / \mathrm{SiO}_{2}(\mathbf{1})$ and $\left[\mathrm{Tb}\left(\mathrm{W}_{5} \mathrm{O}_{18}\right)_{2}\right] / \mathrm{SiO}_{2}$ (2) nanocomposites, respectively, and a shoulder around $290 \mathrm{~nm}$ observed for both materials. The fact that this latter component is present in the spectra of both $\mathrm{Eu}^{3+}$ and $\mathrm{Tb}^{3+}$-based POM, suggests that it may arise from $\mathrm{O} \rightarrow \mathrm{W}$ ligand-to-metal charge transfer (LMCT) state. ${ }^{33}$ In fact, the presence of $\mathrm{O} \rightarrow \mathrm{W}$ LMCT in the same region was recently reported for surfactant encapsulated $\left[\mathrm{EuW}_{10} \mathrm{O}_{36}\right]^{9-}$ polyoxotungstate. ${ }^{23}$ The bands at higher energies should belong to $\mathrm{O} \rightarrow \mathrm{Eu}$ and $\mathrm{O} \rightarrow \mathrm{Tb}$ LMCT states. The excitation of the $\left[\mathrm{Tb}\left(\mathrm{W}_{5} \mathrm{O}_{18}\right)_{2}\right] / \mathrm{SiO}_{2}(2)$ nanocomposite also shows a broad band at $410 \mathrm{~nm}$, probably due to LMCT transitions ascribed to $\mathrm{O} \rightarrow$ $\mathrm{W} / \mathrm{Tb}$ transitions typical of polyoxometalates. ${ }^{28}$

When using the POM-picOH organic-inorganic hybrid as starting material, $\mathrm{Na}_{13}\left[\mathrm{Eu}\left(\mathrm{W}_{5} \mathrm{O}_{18}\right)_{2}(\mathrm{picOH})_{4}\right] \cdot 15 \mathrm{H}_{2} \mathrm{O}$, a POM$\mathrm{picOH} / \mathrm{SiO}_{2}$ core/shell nanostructured material was also obtained (Fig. 1c), with the FTIR and FT-Raman spectra showing extra bands for the organic moiety (see Fig. S1c and S2c in the ESI $\uparrow$ for the spectra of starting POM-picOH). The effect of the organic ligand can be observed in normal digital photographs (Fig. 5) of the solid samples under UV irradiation. The $\left[\mathrm{Eu}\left(\mathrm{W}_{5} \mathrm{O}_{18}\right)_{2}(\mathrm{picOH})_{4}\right] / \mathrm{SiO}_{2}(6)$ nanocomposite shows emission under $366 \mathrm{~nm}$ radiation that is not visually observed for $\left[\mathrm{Eu}\left(\mathrm{W}_{5} \mathrm{O}_{18}\right)_{2}\right] / \mathrm{SiO}_{2}$ (1). The nanocomposites prepared form stable colloids, both in water and in ethanol, whose emission is still observed under a UV lamp at $254 \mathrm{~nm}$ (Fig. 5d).

The effect of incorporating the organic ligand (picOH) in the lanthanide ion excitation path was monitored for the $\left[\mathrm{Eu}\left(\mathrm{W}_{5} \mathrm{O}_{18}\right)_{2}(\mathrm{picOH})_{4}\right] / \mathrm{SiO}_{2}(6)$ nanocomposite. Fig. 4 also shows the excitation spectrum of $\mathbf{6}$ monitored within the ${ }^{5} \mathrm{D}_{0} \rightarrow{ }^{7} \mathrm{~F}_{2}$ transition. The spectrum shows the $\mathrm{O} \rightarrow$ Eu and $\mathrm{O} \rightarrow$ W LMCT bands at around 260 and $290 \mathrm{~nm}$, respectively, already detected for $\left[\mathrm{Eu}\left(\mathrm{W}_{5} \mathrm{O}_{18}\right)_{2}\right] / \mathrm{SiO}_{2}(\mathbf{1})$, and a band between 300 and $400 \mathrm{~nm}$ which arises from the picOH excited states. ${ }^{26,28}$ The temperature decrease from 300 to $14 \mathrm{~K}$, favours the contribution of the picOH excited states relatively to that of the LMCT ones (see Fig. S5 in the ESI $\dagger$ ). The incorporation of the organic counterpart contributes to enhance the $\mathrm{Eu}^{3+}$ sensitization as the low-relative intensity of the ${ }^{7} \mathrm{~F}_{0,1} \rightarrow{ }^{5} \mathrm{D}_{4-2},{ }^{5} \mathrm{G}_{2-6},{ }^{5} \mathrm{~L}_{6} \mathrm{Eu}^{3+}$ intra- $4 \mathrm{f}^{6}$ lines points out, when compared with those in $\left[\mathrm{Eu}\left(\mathrm{W}_{5} \mathrm{O}_{18}\right)_{2}\right] / \mathrm{SiO}_{2}$ (1), in agreement with picOH coordinated to the lanthanide center.

Fig. 6 compares the room temperature emission spectra of the $\left[\mathrm{Eu}\left(\mathrm{W}_{5} \mathrm{O}_{18}\right)_{2}\right] / \mathrm{SiO}_{2}$ (1) and $\left[\mathrm{Tb}\left(\mathrm{W}_{5} \mathrm{O}_{18}\right)_{2}\right] / \mathrm{SiO}_{2}$ (2) nanocomposites under different excitation wavelengths. For excitation wavelengths below $300 \mathrm{~nm}$ the emission spectra display essentially the intra- $4 \mathrm{f}$ lines attributed to the ${ }^{5} \mathrm{D}_{0} \rightarrow{ }^{7} \mathrm{~F}_{0-4}\left(\mathrm{Eu}^{3+}\right)$ and ${ }^{5} \mathrm{D}_{4} \rightarrow{ }^{7} \mathrm{~F}_{6-0}\left(\mathrm{~Tb}^{3+}\right)$ transitions. Increasing the excitation wavelength induces the appearance of a large broad band in the $380-500 \mathrm{~nm}$ region which may be originated within the $\mathrm{SiO}_{2}$ host. The emission spectrum of the hybrid material, 


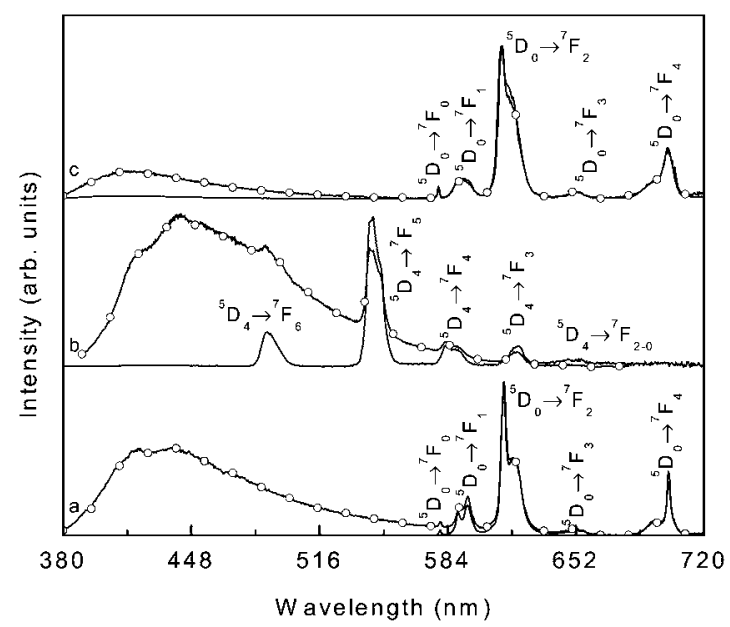

Fig. 6 Room temperature emission spectra of (a) $\left[\mathrm{Eu}\left(\mathrm{W}_{5} \mathrm{O}_{18}\right)_{2}\right] / \mathrm{SiO}_{2}(\mathbf{1})$, (b) $\left[\mathrm{Tb}\left(\mathrm{W}_{5} \mathrm{O}_{18}\right)_{2}\right] / \mathrm{SiO}_{2}(2)$ and (c) $\left[\mathrm{Eu}\left(\mathrm{W}_{5} \mathrm{O}_{18}\right)_{2}(\mathrm{picOH})_{4}\right] / \mathrm{SiO}_{2}(6)$ excited within 250-300 $\mathrm{nm}$ (solid line) and 365-375 $\mathrm{nm}$ (solid line and circles).

$\left[\mathrm{Eu}\left(\mathrm{W}_{5} \mathrm{O}_{18}\right)_{2}(\mathrm{picOH})_{4}\right] / \mathrm{SiO}_{2}$ (6), also depends on the excitation wavelengths; for excitation wavelength below $280 \mathrm{~nm}$ the spectra show the $\mathrm{Eu}^{3+}$ intra- $4 \mathrm{f}^{6}$ lines whereas for higher excitation wavelengths a broad band blue-shifted with respect to that of $\mathbf{1}$ and $\mathbf{2}$ is also detected. This band can be ascribed to the presence of the picOH ligands. ${ }^{26,28}$

Aiming to investigate the influence of the (picOH) ligand on the $\mathrm{Eu}^{3+}$-local coordination, the photoluminescence features of the $\left[\mathrm{Eu}\left(\mathrm{W}_{5} \mathrm{O}_{18}\right)_{2}(\mathrm{picOH})_{4}\right] / \mathrm{SiO}_{2}(\mathbf{6})$ and $\left[\mathrm{Eu}\left(\mathrm{W}_{5} \mathrm{O}_{18}\right)_{2}\right] / \mathrm{SiO}_{2}(\mathbf{1})$ were further studied. To perform this analysis we will focus in the energy of the non-degenerated ${ }^{5} \mathrm{D}_{0} \rightarrow{ }^{7} \mathrm{~F}_{0}$ transition, since this transition is usually related with the covalency degree of the $\mathrm{Eu}-$ O bonds. ${ }^{35-37}$ The energy $\left(E_{00}\right)$ and fwhm $\left(f w h m_{00}\right)$ of the ${ }^{5} \mathrm{D}_{0} \rightarrow$ ${ }^{7} \mathrm{~F}_{0}$ transition were estimated using a single Gaussian fit to the emission spectra. For 1 under direct intra- $4 \mathrm{f}^{6}$ excitation $(465 \mathrm{~nm})$ and via LMCT states $(330 \mathrm{~nm})$ the fit yielded to $E_{00} / f w h m_{00}$ values of $17215.6 \pm 0.1 / 36.3 \pm 0.2 \mathrm{~cm}^{-1}$ and $17230.4 \pm 0.1 /$ $37.7 \pm 0.3 \mathrm{~cm}^{-1}$, respectively. For 6 the $E_{00} / f w h m_{00}$ values are independent of the excitation wavelength being $17251.2 \pm 0.1 /$ $36.8 \pm 0.1 \mathrm{~cm}^{-1}$. The blue-shift of the $E_{0-0}$ line for the hybrid material $\mathbf{6}$ with respect to that of $\mathbf{1}$ suggests that for the former material the $\mathrm{Eu}-\mathrm{O}$ bonds are (on average) less covalent. ${ }^{36-38} \mathrm{Such}$ an assumption is based on the fact that the energy of the ${ }^{5} \mathrm{D}_{0} \rightarrow$ ${ }^{7} \mathrm{~F}_{0}$ transition is related to the so-called nephelauxetic effect, in which the red shift observed for $\mathrm{d}-\mathrm{d}$ and $\mathrm{f}-\mathrm{f}$ energy differences with respect to the free ion, is related to a decrease in the values of the Slater integrals and spin-orbit coupling parameter. ${ }^{36-39}$ The less covalent nature of the $\mathrm{Eu}-\mathrm{O}$ bonds in $\mathbf{6}$ is in good agreement with the presence of picOH in the first coordination sphere of the lanthanide inducing an increase of the $\mathrm{Eu}-\mathrm{O}$ distance. The similar $f_{w h m_{00}}$ values points out an analogous distribution of the $\mathrm{Eu}^{3+}$ ions within materials (1) and (6). At $14 \mathrm{~K}$ the emission spectra of $\left[\mathrm{Eu}\left(\mathrm{W}_{5} \mathrm{O}_{18}\right)_{2}(\mathrm{picOH})_{4}\right] / \mathrm{SiO}_{2}$ (6) resembles that acquired at $300 \mathrm{~K}$, whereas for $\left[\mathrm{Eu}\left(\mathrm{W}_{5} \mathrm{O}_{18}\right)_{2}\right] / \mathrm{SiO}_{2}$ (1) it is observed an increase in the number of Stark components. In particular, it is observed the presence of 5 Stark components for the $\mathrm{D}_{0} \rightarrow{ }^{7} \mathrm{~F}_{1}$ transition under LMCT excitation (Fig. S6 in the ESI $\dagger$ ), supporting the presence of a second $\mathrm{Eu}^{3+}$ local environment, which is thermally quenched at room temperature.
The ${ }^{5} \mathrm{D}_{0}\left(\mathrm{Eu}^{3+}\right)$ and ${ }^{5} \mathrm{D}_{4}\left(\mathrm{~Tb}^{3+}\right)$ lifetime values of the $\left[\mathrm{Eu}\left(\mathrm{W}_{5} \mathrm{O}_{18}\right)_{2}\right] / \mathrm{SiO}_{2} \quad(\mathbf{1}),\left[\mathrm{Eu}\left(\mathrm{W}_{5} \mathrm{O}_{18}\right)_{2}(\mathrm{picOH})_{4}\right] / \mathrm{SiO}_{2} \quad(\mathbf{6})$ and $\left[\mathrm{Tb}\left(\mathrm{W}_{5} \mathrm{O}_{18}\right)_{2}\right] / \mathrm{SiO}_{2}$ (2) were measured at $300 \mathrm{~K}$ under direct intra- $4 f^{6}(393 \mathrm{~nm})$ and intra- $4 \mathrm{f}^{8}(377 \mathrm{~nm})$ excitation, respectively, by monitoring the more intense emission line. All the curves are well reproduced by a single exponential function (not shown) yielding lifetime values of $0.736 \pm 0.003,0.319 \pm 0.003$ and $0.198 \pm 0.002 \mathrm{~ms}$ for $\mathbf{1}, \mathbf{6}$ and $\mathbf{2}$, respectively.

The photoluminescence features of $\mathrm{Eu}^{3+} / \mathrm{Tb}^{3+}$ and $\mathrm{Eu}^{3+} / \mathrm{Gd}^{3+} \mathrm{co}-$ doped nanoparticles were also investigated in the 14 $300 \mathrm{~K}$ temperature range. The emission features of the $\left[\mathrm{Eu}\left(\mathrm{W}_{5} \mathrm{O}_{18}\right)_{2} \mathrm{~Tb}\left(\mathrm{~W}_{5} \mathrm{O}_{18}\right)_{2}\right] / \mathrm{SiO}_{2}$ (4) nanocomposite (Fig. 7) are strongly dependent on the temperature. At room temperature the emission resembles that of the single lanthanide-doped $\left[\mathrm{Eu}\left(\mathrm{W}_{5} \mathrm{O}_{18}\right)_{2}\right] / \mathrm{SiO}_{2}(\mathbf{1})$. At $14 \mathrm{~K}$ the $\mathrm{Tb}^{3+}$ ions are optically active, so that the emission results from the overlap of the $\mathrm{Eu}^{3+}$ and $\mathrm{Tb}^{3+}$ ${ }^{5} \mathrm{D}_{0} \rightarrow{ }^{7} \mathrm{~F}_{0-4}$ and ${ }^{5} \mathrm{D}_{4} \rightarrow{ }^{7} \mathrm{~F}_{6,5}$ transitions, respectively, superimposed on a broad band (Fig. 7). The dependence of the ${ }^{5} \mathrm{D}_{4}$ emission with temperature evidences the presence of thermal deactivation mechanisms, which for lanthanide ions is often ascribed to LMCT states. ${ }^{40}$ The fact that the ${ }^{5} \mathrm{D}_{4}$ level is located above the ${ }^{5} \mathrm{D}_{0}$ one, thus energetically closer to the LMCT states, favours the deactivation of the $\mathrm{Tb}^{3+}$ ions. The excitation spectra were monitored within the $\mathrm{Eu}^{3+}$ and $\mathrm{Tb}^{3+5} \mathrm{D}_{0} \rightarrow{ }^{7} \mathrm{~F}_{4}$ and ${ }^{5} \mathrm{D}_{4} \rightarrow{ }^{7} \mathrm{~F}_{5}$ transitions, respectively (inset of Fig. 7), showing a series of $\mathrm{Eu}^{3+}$ intra- $4 \mathrm{f}^{6}$ and $\mathrm{Tb}^{3+}$ intra- $4 \mathrm{f}^{8}$ lines, respectively, and a broad band with two components at $290 \mathrm{~nm}$ attributed to the $\mathrm{O} \rightarrow$ W LMCT band and a component at $330 \mathrm{~nm}$ not present in single lanthanide doped nanoparticles. The non-observation of the $\mathrm{Tb}^{3+}$ excited levels in the excitation spectra monitored within the $\mathrm{Eu}^{3+}$ intra- $4 \mathrm{f}^{6}$ transitions is a clear evidence that no effective $\mathrm{Tb}^{3+}$-to-Eu ${ }^{3+}$ energy transfer occurs at $14 \mathrm{~K}$ (as also observed at room temperature).

The photoluminescence of the $\left[\mathrm{Eu}\left(\mathrm{W}_{5} \mathrm{O}_{18}\right)_{2} \mathrm{Gd}\left(\mathrm{W}_{5} \mathrm{O}_{18}\right)_{2}\right] / \mathrm{SiO}_{2}$ (5) nanoparticles in the 14-300 K temperature range (not shown) resembles the above mentioned features of the $\left[\mathrm{Eu}\left(\mathrm{W}_{5} \mathrm{O}_{18}\right)_{2}\right]$ $\mathrm{SiO}_{2}$ (1) nanoparticles. Therefore, similarly to that found for the $\mathrm{Eu}^{3+} / \mathrm{Tb}^{3+}$ co-doped nanoparticles no effective interaction exists between $\mathrm{Gd}^{3+}$ and $\mathrm{Eu}^{3+}$ ions.

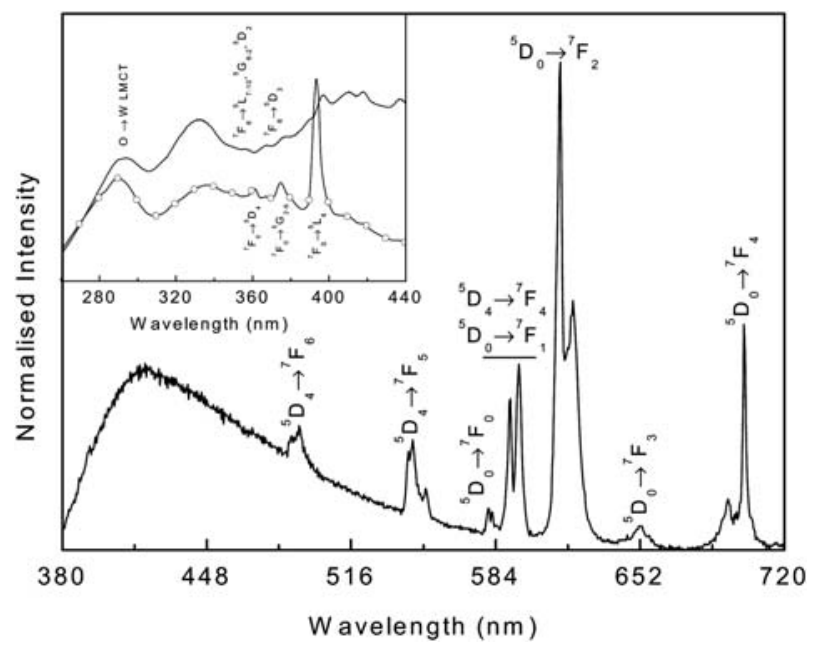

Fig. 7 Emission spectrum $(14 \mathrm{~K})$ of $\left[\mathrm{Eu}\left(\mathrm{W}_{5} \mathrm{O}_{18}\right)_{2} \mathrm{~Tb}\left(\mathrm{~W}_{5} \mathrm{O}_{18}\right)_{2}\right] / \mathrm{SiO}_{2}(4)$ excited at $340 \mathrm{~nm}$. The inset shows the excitation spectra monitored at $544 \mathrm{~nm}$ (solid line) and $701 \mathrm{~nm}$ (solid line and circles). 
To further quantify the emission features of all the composite nanoparticles, the absolute emission quantum yield was measured for direct intra-4f excitation $\left(\mathrm{Tb}^{3+}, 377 \mathrm{~nm}\right.$ and $\mathrm{Eu}^{3+}$, $395 \mathrm{~nm})$, via the LMCT (260-290 nm) states and through the picOH excited states for the hybrid POM. For all the materials, the maximum quantum yield value was attained under UV excitation at $260 \mathrm{~nm}$. For the $\left[\mathrm{Eu}\left(\mathrm{W}_{5} \mathrm{O}_{18}\right)_{2}\right] / \mathrm{SiO}_{2}(\mathbf{1})$ a value of 0.08 was measured. The co-doping of the $\left[\mathrm{Eu}\left(\mathrm{W}_{5} \mathrm{O}_{18}\right)_{2}\right] / \mathrm{SiO}_{2}$ nanoparticles with $\mathrm{Gd}^{3+}$ did not affect the quantum yield values, whereas the $\mathrm{Tb}^{3+}$ incorporation lead to a decrease to 0.04 . For $\left[\mathrm{Tb}\left(\mathrm{W}_{5} \mathrm{O}_{18}\right)_{2}\right] / \mathrm{SiO}_{2}(2)$ the quantum yield value is lower than the detection limits of our equipment $(0.01)$. For the $\left[\mathrm{Eu}\left(\mathrm{W}_{5} \mathrm{O}_{18}\right)_{2}-\right.$ $\left.(\mathrm{picOH})_{4}\right] / \mathrm{SiO}_{2}(6)$ nanocomposite, a quantum yield decrease to 0.05 was found after coordination of the picOH organic ligand to the lanthanide ion, which is in good agreement with the presence of extra non-radiative channels in 6 compared to $\left[\mathrm{Eu}\left(\mathrm{W}_{5} \mathrm{O}_{18}\right)_{2}\right] /$ $\mathrm{SiO}_{2}(\mathbf{1})$; similar values $(0.031-0.034)$ have been reported for a polyoxometalate-based material with $\mathrm{K}_{13}[\mathrm{Eu}(\mathrm{Si}$ $\left.\left.\mathrm{Mo}_{x} \mathrm{~W}_{11-x} \mathrm{O}_{39}\right)_{2}\right] .{ }^{24}$

\section{Conclusions}

Recent advances in chemical strategies towards nanoparticles led to the development of non-conventional luminescent bio-labels, which include, for example, diverse types of quantum dots and silica containing dyes. ${ }^{14,41}$ In this work we have described the synthesis of well-defined core/shell nanoparticles comprising a core of lanthanopolyoxotunsgstates encapsulated by silica shells, which in principle can be further exploited as alternative bio-labels. The visible photoluminescence of the $\mathrm{POM} / \mathrm{SiO}_{2}$ systems can be tuned by modifying the coordination sphere of the lanthanopolyoxometalate and/or its chemical composition. Though there is an inherent chemical complexity of some POM species inside the reacting microemulsions, detailed photoluminescence studies can contribute to elucidate the lanthanide chemistry occurring in these systems, as shown in this work.

\section{Acknowledgements}

The authors thank Fundação para a Ciência e a Tecnologia (Portugal) for funding under the POCI 2010 and PTDC programs and FEDER (POCI/QUI/58887/2004 and PTDC/ QUI/67712/2006), and for post graduation grants to $\mathrm{CMG}$ (SFRH/BD/30137/2006) and PCRSS (SFRH/BPD/14954/2004). We thank Dr Marc Willinger and the RNME (National Electronic Microscopy Network, Portugal) for HRTEM images.

\section{Notes and references}

1 Y. Piao, A. Burns, J. Kim, U. Wiesner and T. Hyeon, Adv. Funct. Mater., 2008, 18, 3745.

2 A. Burns, H. Owb and U. Wiesner, Chem. Soc. Rev., 2006, 35, 1028.

3 A. A. Burns, J. Vider, H. Ow, E. Herz, O. Penate-Medina, M. Baumgart, S. M. Larson, U. Wiesner and M. Bradbury, Nano Lett., 2009, 9, 442.

4 T. Deng, J. Li, J. Jiang, G. Shen and R. Yu, Chem.-Eur. J., 2007, 13, 7725.

5 T. Deng, J. Li, J. Jiang, G. Shen and R. Yu, Adv. Funct. Mater., 2006, 16, 2147.

6 W. Stöber, A. Fink and E. Bohn, J. Colloid Interface Sci., 1968, 26, 62.

7 Z. Ye, M. Tan, G. Wang and J. Yuan, J. Mater. Chem., 2004, 14, 851.
8 P. Mulvaney, L. M. Liz-Marzán, M. Giersig and T. Ung, J. Mater. Chem., 2000, 10, 1259.

9 L. Li, E. Shi, G. Choo, Z. Liu and J. Xue, Chem. Phys. Lett., 2008, 461, 114

10 J. Wang, G. Liu and Y. Lin, Small, 2006, 2, 1134.

11 A. Bumb, M. W. Brechbiel, P. L. Choyke, L. Fugger, A. Eggeman, D. Prabhakaran, J. Hutchinson and P. J. Dobson, Nanotechnology, 2008, 19, 335601.

12 H. Zhang, Y. Xu, W. Yang and Q. Li, Chem. Mater., 2007, 19, 5875.

13 C. Louis, R. Bazzi, C. A. Marquette, J.-L. Bridot, S. Roux, G. Ledoux, B. Mercier, L. Blum, P. Perriat and O. Tillement, Chem. Mater., 2005, 17, 1673.

14 R. He, X. You, J. Shao, F. Gao, B. Pan and D. Cui, Nanotechnology, 2007, 18, 315601.

15 S.-H. Hu, S.-Y. Chen, D.-M. Liu and C.-S. Hsiao, Adv. Mater., 2008, 20, 2690.

16 I. I. Slowing, B. G. Trewyn, S. Giri and V. S.-Y. Lin, Adv. Funct. Mater., 2007, 17, 1225.

17 M. Clemente-León, E. Coronado, A. Soriano-Portillo, C. Mingotaud and J. M. Dominguez-Vera, Adv. Colloid Interface Sci., 2005, 116, 193.

18 F. L. Sousa, A. S. Ferreira, R. A. S. Ferreira, A. M. V. Cavaleiro, L. D. Carlos, H. I. S. Nogueira and T. Trindade, J. Alloys Compd., 2004, 374, 371.

19 S. Liu, D. G. Kurth, B. Bredenkötter and D. Volkmer, J. Am. Chem. Soc., 2002, 124, 12279.

20 F. L. Sousa, A. C. A. S. Ferreira, R. A. S. Ferreira, A. M. V. Cavaleiro, L. D. Carlos, H. I. S. Nogueira, J. Rocha and T. Trindade, J. Nanosci. Nanotechnol., 2004, 4, 214.

21 F. L. Sousa, M. Pillinger, R. A. S. Ferreira, C. M. Granadeiro, A. M. V. Cavaleiro, J. Rocha, L. D. Carlos, T. Trindade and H. I. S. Nogueira, Eur. J. Inorg. Chem., 2006, 2006, 726.

22 S. Yin, H. Sun, Y. Yan, W. Li and L. Wu, J. Phys. Chem. B, 2009, 113, 2355.

23 W. Qi, H. Li and L. Wu, Adv. Mater., 2007, 19, 1983.

24 M. Green, J. Harries, G. Wakefield and R. Taylor, J. Am. Chem. Soc., $2005, \mathbf{1 2 7}, 12812$.

25 G. Hungerford, M. Green and K. Suhling, Phys. Chem. Chem. Phys, 2007, 9, 6012.

26 (a) P. C. R. Soares-Santos, H. I. S. Nogueira, V. Félix, M. G. B. Drew, R. A. S. Ferreira, L. D. Carlos and T. Trindade, Chem. Mater., 2003, 15, 100; (b) K. O. Iwu, P. C. R. Soares-Santos, H. I. S. Nogueira, L. D. Carlos and T. Trindade, J. Phys. Chem. C, 2009, 113, 7567.

27 R. A. S. Ferreira, S. S. Nobre, C. M. Granadeiro, H. I. S. Nogueira, L. D. Carlos and O. L. Malta, J. Lumin., 2006, 121, 561.

28 C. M. Granadeiro, R. A. S. Ferreira, P. C. R. Soares-Santos, L. D. Carlos and H. I. S. Nogueira, J. Alloys Compd., 2008, 451, 422.

29 R. D. Peacock and T. J. R. Weakley, J. Chem. Soc. A, 1971, 1836.

30 C. Rocchiccioli-Deltcheff, M. Fournier, R. Franck and R. Thouvenot, Inorg. Chem., 1983, 22, 207.

31 A. M. V. Cavaleiro, J. D. P. Jesus and H. I. S. Nogueira, in Metal Clusters in Chemistry, ed. P. Braunstein, L. A. Oro and P. R. Raithby, Wiley-VCH, Weinheim, Germany, 1999, vol. 1, pp. 444-458.

32 Y. Lu, Y. Yin, B. T. Mayers and Y. Xia, Nano Lett., 2002, 2, 183.

33 (a) G. Blasse, G. J. Dirksen and F. Zonnevijlle, J. Inorg. Nucl. Chem., 1981, 43, 2847; (b) R. Ballardini, Q. G. Mulazzani, M. Venturi, F. Bolletta and V. Balzani, Inorg. Chem., 1984, 23, 300; (c) T. Yamase and H. Naruke, J. Chem. Soc., Dalton Trans., 1991, 285; (d) J. Wang, H. S. Wang, L. S. Fu, F. Y. Liu and H. J. Zhang, Thin Solid Films, 2002, 414, 256.

34 M. J. E. Rodrigues, F. A. A. Paz, R. A. S. Ferreira, L. D. Carlos and H. I. S. Nogueira, Mater. Sci. Forum, 2006, 514-516, 1305.

35 S. T. Frey and W. D. W. Horrocks, Inorg. Chim. Acta, 1995, 229, 383.

36 O. L. Malta, H. J. Batista and L. D. Carlos, Chem. Phys., 2002, 282, 21.

37 L. D. Carlos, O. L. Malta and R. Q. Albuquerque, Chem. Phys. Lett., 2005, 415, 238.

38 L. D. Carlos and A. L. L. Videira, J. Chem. Phys., 1994, 101, 8827.

39 C. K. Jørgensen, Prog. Inorg. Chem., 1962, 4, 73.

40 B. Canny and D. Curie, in Advances in Nonradiative Processes in Solids, ed. B. Di Bartolo, Plenum Press, New York, 1991, vol. 249, pp. 1-28.

41 M. V. Yezhelyev, A. Al-Hajj, C. Morris, A. I. Marcus, T. Liu, M. Lewis, C. Cohen, P. Zrazhevskiy, J. W. Simons, A. Rogatko, S. Nie, X. Gao and R. M. O'Reagan, Adv. Mater., 2007, 19, 3146. 